\title{
Landscape- and local- level variables affect monarchs in Midwest grasslands
}

\author{
Anna Skye Bruce ( $\square$ hamsberger@wisc.edu ) \\ University of Wisconsin-Madison \\ Wayne E. Thogmartin \\ US Geological Survey Upper Midwest Environmental Sciences Center \\ Chris Trosen \\ US Fish and Wildlife Service \\ Karen Oberhauser \\ University of Wisconsin Madison \\ Claudio Gratton \\ University of Wisconsin-Madison
}

Research Article

Keywords: monarch, landscape, restoration, ecology, local vs. landscape effects, patch size

Posted Date: April 30th, 2021

DOI: https://doi.org/10.21203/rs.3.rs-346846/v1

License: () This work is licensed under a Creative Commons Attribution 4.0 International License. Read Full License

Version of Record: A version of this preprint was published at Landscape Ecology on October 15th, 2021. See the published version at https://doi.org/10.1007/s10980-021-01341-4. 


\section{Abstract}

Context It is estimated that over one billion milkweed stems need to be restored to sustain the eastern North American migratory population of monarch butterflies; where and in what context the stems should be placed on the landscape is key to addressing habitat deficits. Objectives We assessed how the amount of appropriate habitat surrounding a particular patch of monarch habitat affects monarch presence and reproduction. To ensure that habitat restoration efforts are targeted towards areas that maximize monarch population growth, it is important to understand the effects of landscape heterogeneity on monarch occurrence in habitat patches (i.e. grasslands with milkweeds) across the landscape. Methods Over two summers (2018-2019), we surveyed monarch adults, larvae, and eggs at sixty grassland sites in Wisconsin that varied in patch size and landscape context (proportion grassland, forest edge density, and road density). We also estimated milkweed density and floral richness to characterize local patch quality. Results Adult monarch abundance was highest at patches with the lowest proportion of surrounding grassland and lowest road density, and was heavily influenced by patch quality variables. Egg and larva density in a patch increased with milkweed density and floral richness within a patch. Patch size was unrelated to monarch abundance. Conclusions These results suggest that optimal sites for monarch habitat restoration are within landscapes with less surrounding habitat and that high milkweed density and floral richness should be conservation goals.

\section{Introduction}

The eastern North American migratory subpopulation (hereafter "population") of monarch butterflies (Danaus plexippus) has significantly declined over the last two decades, prompting a petition to list the species as federally threatened (Center for Biological Diversity et al. 2014). Subsequently, it was determined that listing was warranted but precluded by prioritization of species at higher risk of extinction (U. S. Fish and Wildlife Service 2020 ). The population is estimated to have a high likelihood of quasi-extinction over the next 20 years (Semmens et al. 2016). The loss of summer breeding habitat has been implicated as an important driver of the decline (Pleasants \& Oberhauser 2013, Pleasants 2017, Thogmartin et al. 2017b, Saunders et al. 2018), as have weather-related and other factors that are likely to affect monarch survival and reproduction throughout their migratory cycle (Altizer \& Oberhauser 1999, Oberhauser 2012, Thogmartin et al. 2017c, Saunders et al. 2018). Breeding habitat for monarchs requires milkweed plants (Asclepias spp.), the host plants of monarch larvae, and additional flower nectar resources used by adult butterflies.

Twenty years ago, a significant portion of monarchs originating in the Upper Midwest utilized milkweed found in agricultural habitats (Oberhauser et al. 2001). Since the introduction of genetically modified herbicide-tolerant row crops, milkweed within crop fields has largely disappeared, significantly reducing the availability of monarch host plants in agricultural settings (Pleasants \& Oberhauser 2013, Thogmartin et al. 2017b, Stenoien et al. 2018). Accordingly, restoration of non-agricultural sites, such as perennial grasslands, is a focus of many monarch conservation efforts.

Recent estimates of the extent of habitat restoration needed to return monarchs to a sustainable population size require the planting of $1.3-1.6$ billion stems of milkweed in the Midwest (Pleasants 2017, Thogmartin et al. 2017a). Conservation efforts by government, non-profit, and private organizations are aimed at getting milkweed stems back on the landscape to increase breeding habitat for monarchs and, consequently, the number of monarchs returning south to overwintering sites in Mexico. Recent demographic analyses suggest that adding milkweed in the Upper Midwestern U.S. will have a large impact on the monarch population (Oberhauser et al. 2017).

This approach assumes that monarchs are able to locate and utilize milkweed stems equally across all types of landscapes. However, it is likely that adult monarchs will be affected by landscape characteristics as they search for patches of milkweed on which to oviposit. One characteristic that could affect monarch abundance at a given milkweed patch is the amount of surrounding grassland. Monarchs are able to visually detect milkweed from several meters away (Garlick 2007) and olfactorily detect milkweed and nectar plants from up to several hundred meters away (Grant et al. 2018, Blackiston et al. 2011). In addition, adult summer breeding monarchs can fly $15 \mathrm{~km}$ daily (Zalucki et al. 2016) and it is likely that their flight patterns differ in habitat-rich versus habitat-poor landscapes (Zalucki \& Kitching 1982b, Zalucki 1983). Since monarch perceptual range is limited, isolated patches of habitat (i.e., in landscapes with few additional grassland patches) may be harder to locate and, therefore, landscape composition could affect monarch abundance within a patch.

While little is known about how monarchs locate or choose habitat patches, simulations by Grant et al. (2018) suggest that establishing many small patches of habitat, rather than few large patches, will yield the highest numbers of eggs laid by individual monarchs. This result suggests that both patch size and the distribution of patches on the landscape contribute to monarch abundance. However, there are currently no empirical data to test the hypothesized relationship between monarch abundance and landscape at a spatial scale relevant to monarch perceptual abilities.

Patch size can also influence butterfly movement based on individuals' ability to navigate an unfavorable landscape, but the directionality of this effect varies based on species. Established theory suggests larger patches are better at supporting specialist herbivore populations (Root 1973, Hill et al. 1996), and monarch studies investigating the effect of patch size indicate that larger patches contain more monarch adults (Davis et al. 2007, Dinsmore et al. 2019). However, other studies suggest that small patches can have higher immigration rates than large patches for some butterfly species (Shultz \& Crone 2005), and that monarchs might benefit from small patches (Grant et al. 2018). In other cases, occupancy probability is similar for small and large patches, but as patch isolation increases, large patches have a higher likelihood of occupancy (Matter et al. 2005). Conflicting evidence from previous studies highlights the need to elucidate the relative importance of patch size and patch isolation on monarch abundance, and interactions between the two. 
Monarchs are likely to use patch-level characteristics, such as the quality and quantity of host plants and nectar sources, to assess whether to remain in or leave a patch. Both milkweed density (Pleasants \& Oberhauser 2013) and the diversity and abundance of flowering plants (Potts et al. 2009)

likely influence monarch use of patches.

We performed a 2-year study in the Upper Midwestern USA (Wisconsin) to examine the relationship between monarch abundance in grassland habitat patches and both landscape and patch characteristics. By using standardized sampling protocols and intentionally selecting grassland sites to span a range of landscape contexts and patch sizes, we tested the independent effects of landscape and patch-level characteristics on monarch abundance.

At the landscape level, we used the proportion of grassland in the surrounding landscape as a proxy for additional available monarch habitat, given that most grasslands have milkweeds and nectar plants (Thogmartin et al. 2017b). Patches of grassland habitats situated in landscapes containing a greater amount of additional grassland area might have relatively greater monarch abundance, due to longer retention of monarchs (Zalucki \& Kitching, 1982b; Zalucki, 1983) and an increase in the likelihood of spillover from nearby habitat patches (e.g., Grant et al. 2018). On the other hand, grassland patches situated in landscapes without large amounts of alternative habitat might attract more monarchs and monarchs might stay longer in them due to the lack of nearby alternatives. As a null hypothesis, we posited that the composition of landscape surrounding a habitat patch does not affect monarch density within the patch, if monarchs move across the landscape in a way that is unaffected by the amount of grassland habitat through which they are flying.

At the patch level, we hypothesized that monarch density is inversely related to patch size, with higher density in small patches, in accordance with models suggesting that small patches are more valuable for monarch recruitment (Grant et al. 2018, Zalucki et al. 2016). We also hypothesized that patch-level characteristics such as the density of host milkweed plants for larvae and nectaring plants for adult monarchs would be associated with greater monarch density (eggs, larvae, and adults). Finally, it is possible that local, patch-level characteristics may interact with broad-scale landscape characteristics to influence monarch abundance (Grant et al. 2018, Tscharntke et al. 2002, Davis et al. 2007). For example, although small grassland habitat patches may generally have higher monarch densities than large patches, colonization of these small patches may be dependent on the amount of surrounding grassland in the landscape, with small patches benefiting more from greater potential source populations in the landscape than large patches.

\section{Methods}

\section{Site selection}

Sixty sites in Wisconsin (WI), USA were selected for surveys: 31 in northern and 29 in southern WI (Appendix A). Sites were chosen from a broader list of potential properties to which we could gain access and permission for sampling, and generated from several sources: the Wisconsin Department of Natural Resources, the U. S. Fish and Wildlife Service, and The Nature Conservancy. All properties contained patches of land cover classified as grassland, pasture/hay, and/or herbaceous wetland (hereafter "grassland") based on the digital raster-based land cover classification map from the 2016 National Land Cover Database (Dewitz 2019). To ensure that sites spanned a range of local and landscape characteristics of interest, the properties were selected from a large pool of potential sites in this region to span a range of patch sizes ( $0.9-700$ ha of contiguous grassland) and grassland context (1-45\% grassland at $10 \mathrm{~km}$ buffer around each patch) and to ensure that these variables were uncorrelated $(r=0.36$, Appendix B).

All sites were surveyed in both 2018 and 2019, with each site surveyed in three time periods (early: approximately June 1-June 22, middle: approximately June 23-July 14, and late: approximately June 15-August 9) over the course of each summer field season to account for phenological changes in vegetation and monarch presence in the Midwest (Oberhauser et al. 2017).

\section{Landscape-level and area-based characteristics}

We used a digital raster-based land cover classification map with a grain size of $30 \mathrm{~m} \times 30 \mathrm{~m}$ to determine, for a $10 \mathrm{~km}$-radius circular buffer surrounding each survey site, the proportion of grassland habitat (National Land Cover Dataset 2016). The 10-km assessment was chosen to correspond with the estimated daily travel maximum for a female adult monarch (Zalucki 2016, see also Dinsmore et al. 2019). Area-based landscape metrics, specifically the proportion of suitable habitat in the landscape within a given buffer, are reliable metrics of patch isolation when compared to simple distance-based or omni-directional distance-based metrics (Bender et al. 2003, Fahrig 2013).

We calculated landscape metrics using the landscapemetrics and tigris packages in R (R Core Team 2019, Hesselbarth et al. 2019, Walker 2020). Using the Ism_c_pland function, we evaluated the proportion of grassland within $10 \mathrm{~km}$ of each survey site. Because roadways can serve as corridors along which monarchs reach given habitat patches, we calculated road density (meters of road per km²) within $10 \mathrm{~km}^{2}$ of a site to quantify additional potential habitat suitable for monarch recruitment in the landscape (United States Census Bureau 2019). We included forest edges, which represent potential monarch habitat and also barriers to monarch movement (Ries \& Debinski 2001), as a variable by calculating forest edge density within 10 $\mathrm{km}$ of each site using the /sm_c_ed function (Hesselbarth et al. 2019). To measure the size of each patch, we calculated the amount of contiguous grassland at a survey site using the Ism_p_area function (Hesselbarth et al. 2019).

\section{Patch quality characteristics}


We measured several variables during each site visit: milkweed stem density (stems per $\mathrm{m}^{2}$ ), milkweed species richness (number of unique species), and floral species richness (number of unique species in bloom) (See Table 1 and Appendix C). We used survey protocols of the Integrated Monarch Monitoring Protocol (Cariveau et al. 2019). In brief, this approach consists of setting up a rectangular sampling plot measuring $50 \times 200 \mathrm{~m}$ and consisting of four transects which make up the $500 \mathrm{~m}$ perimeter of each plot. For each site, we randomly placed the survey plot in a grassland habitat within each site using the Create Random Points tool in ArcGIS (Esri 2018). All blooming plants within a meter of the transect lines were identified to species. We assessed milkweed density by placing a $0.5 \mathrm{~m} \times 1 \mathrm{~m}$ quadrat on both sides of each transect line every $5 \mathrm{~m}$ along the $500 \mathrm{~m}$ perimeter, creating a $1 \mathrm{~m}^{2}$ subplot at every $5 \mathrm{~m}$ mark (100 total subplots per survey plot). We recorded the number of milkweed stems rooted within the bounds of the quadrat, and estimated milkweed density as stems $/ \mathrm{m}^{2}$.

Table 1

Summary of milkweed presence by species at 60 study sites.

\begin{tabular}{|lllll|}
\hline Species & $\begin{array}{l}\text { Total individual plants } \\
\text { found }\end{array}$ & $\begin{array}{l}\text { \# sites where } \\
\text { present }\end{array}$ & $\begin{array}{l}\text { \% sites where } \\
\text { present }\end{array}$ & $\begin{array}{l}\text { Mean plant density (when present, } \\
\text { plants } / \mathbf{m}^{2} \text { ) }\end{array}$ \\
\hline A. syriaca & 40,742 & 59 & 98.3 & 0.429 \\
\hline A. verticillata & 18,591 & 30 & 50.0 & 0.629 \\
\hline A. tuberosa & 283 & 8 & 13.3 & 0.011 \\
\hline A. incarnata & 92 & 12 & 20.0 & 0.003 \\
\hline A. viridiflora & 62 & 4 & 6.7 & 0.005 \\
\hline $\begin{array}{l}\text { A. } \\
\text { amplexicaulis }\end{array}$ & 33 & 5 & 8.3 & 0.002 \\
\hline
\end{tabular}

We excluded Asclepias verticillata from milkweed and monarch metrics (except for Table 1) following Lukens et al. (2020) and Kasten et al. (2016). This exclusion was due to the large number of stems of this species found at some patches, which, if included, artificially inflated the stem density estimates because of $A$. verticillata's small biomass compared to other Asclepias species. Some of our survey areas contained up to 4,000 stems of $A$. verticillata (the next most common species, $A$. syriaca, had a maximum of 808 stems), making it difficult not only to compare to other species, but to count and search for monarch eggs and larvae (hereafter "immatures") thoroughly and with the same effort. Half of our sites contained $A$. verticillata.

\section{Monarch surveys}

We used a modified Pollard walk to count monarch adults within $5 \mathrm{~m}$ of each transect (Pollard 1977, IMMP 2018). Surveys of monarch adults were conducted only when environmental conditions were optimal for butterfly activity: $0900-1600$ hours, temperature $18-33^{\circ} \mathrm{C}$, wind speeds $<39 \mathrm{~km} / \mathrm{h}$, and no precipitation. We conducted Pollard walks before the patch quality characterization so that the adult count was not influenced by vegetation surveyors.

Surveys of monarch immatures were conducted during a second perimeter walk of the plot, in conjunction with the survey of patch-quality characteristics (above). We walked along the perimeter of the survey plot and examined all milkweed stems within one meter of the transect lines. Each milkweed stem encountered was inspected for monarch immatures. In most cases, each milkweed stem encountered (117 \pm 112 stems, mean \pm SD) was inspected for monarch immatures, although we stopped inspecting after 200 stems at some high milkweed density sites to avoid observer fatigue.

We calculated immature monarch abundance per stem (immatures observed / stems inspected). This value provides a familiar metric for land managers interested in predicting the number of monarchs their habitat restoration could produce based on the number of stems that are feasible to plant, in accordance with national conservation goals expressed in the number of new milkweed stems needed to restore the monarch population (Thogmartin et al. 2017a). In addition, we calculated monarch immature density (immatures / $\mathrm{m}^{2}$ ) by multiplying immature abundance per stem (immatures / stem) by milkweed stem density (stems $/ \mathrm{m}^{2}$ ). This metric provides an estimate of the abundance of subadult monarchs on an areabased, patch-level spatial scale rather than a per stem metric.

\section{Statistical analysis}

We used multiple regression to assess the relationship between monarch abundance and the two variables of interest: landscape grassland and patch area. Response variables were measured as the count of adult monarchs, monarch immatures per milkweed stem, and monarch immatures per $\mathrm{m}^{2}$.

We created three separate mixed-effects regression models to assess whether landscape characteristics (surrounding proportion of grassland, forest edge density, road density) and local, patch-level characteristics (patch size, milkweed density, floral richness) predicted the response variables. We included the interaction between the proportion of grassland in the landscape and patch size to examine whether patch size effects varied by landscape context. To facilitate comparison of covariate effects ranging over different scales, predictor variables were scaled using the scale function in R (R Core Team 2019). 
To account for additional temporal and spatial variation, other covariates in the full models included year (2018, 2019), survey period (early, middle, late) within the season, and a random effect of site nested within region (north or south Wisconsin) to account for repeated samples and different regions. There was no evidence of spatial autocorrelation between sites according to a Moran's test performed using the Moran./function in the package ape (Paradis \& Schliep 2018). Predictor variables were uncorrelated in the full models $(\mathrm{VIF}<3)$.

To address overdispersion issues in the model for monarch adults, we used the negative binomial family of distributions in the $g / m m T M B$ package (Brooks et al. 2017) to model the data. The response data for the adult count model were zero-inflated; to account for this inflation we used a zeroinflation formula in models for milkweed density and floral richness. For the models predicting monarch egg and larva density, we used the Tweedie family of distributions (Shono 2008). The Tweedie family of distributions accommodates zero inflation, so there was no need for a separate zeroinflation component in these models. For model selection, we passed each full model through the dredge function in the MuMIn package (Bartoń 2019), reporting models with $\triangle \mathrm{AIC}<2.1$ from the best-fit model as competing models (Akaike's Information Criterion; Burnham and Anderson, 2002). Model assumptions and fit were evaluated, in part, with the DHARMa package (Hartig 2020). We calculated $\mathrm{R}^{2}$ values with the $r 2$ function in the performance package (Lüdecke et al. 2020).

\section{Results}

\section{Site Characteristics}

Our study sites varied in size from $0.9-700$ ha of contiguous grassland ( $93 \pm 138$ ha; mean, SD), and the area within $10 \mathrm{~km}$ of them contained $1-45 \%$ grassland (21 $\pm 8 \%$; mean, SD) (Appendix B). All sites contained at least some milkweed (Table 1), and we observed six different milkweed species overall (mean $=1.83$ species per site), with a mean milkweed density of 0.434 stems per $\mathrm{m}^{2}$. $A$. syriaca was the most abundant, present on all but one of our study sites (mean $=0.429$ stems per $\mathrm{m}^{2}$ ). On average, there were 8.6 blooming plant species per site (range $\left.=0-24\right)$. We observed at least one adult monarch during $58 \%$ of our visits, and at least one immature monarch during $71 \%$ of our visits.

\section{Adult monarch abundance}

The full model with milkweed density and floral richness in the zero-inflation formula had the lowest AIC when compared with other combinations of variables. The best-fit model and all three competing models $(\triangle \mathrm{AIC}<2.1)$ predicting adult monarch abundance at a patch included the landscape-level variables of surrounding grassland and road density as well as local-scale variables of milkweed density, floral richness, and survey period (Table 2 , Fig. 1). The amount of grassland in the surrounding $10 \mathrm{~km}$ had a negative association with adult abundance (Fig. 1A), as did road density (Fig. 1B). Within a patch, milkweed density and floral richness both had a positive relationship with monarch abundance (Fig. 1C, D). In addition, we observed more adults during the second survey of the season than the earlier or later surveys. The effects of these predictors were of approximately equal magnitude. Other variables (forest edge density, patch size, year of survey, and the interaction effect between landscape grassland and patch size) were never or rarely present in the top models, and their coefficients were small when they were included.

Table 2

Results of the four best-fit models $(\Delta \mathrm{AIC}<2.1)$ predicting relationships between the number of adult monarchs observed at a patch and predictor variables. Values are the scaled parameter estimates for continuous variables, and order of levels for categorical variables (survey period, year).

Dashes indicate that the covariate was excluded from the model. Significant predictor variables $(p<0.05)$ in the full model are denoted with an asterisk. The interaction of patch size $\times$ surrounding grassland is not listed because it did not appear in any of the ten best-fit models.

\begin{tabular}{|c|c|c|c|c|c|c|c|c|c|c|c|c|}
\hline \multirow[b]{2}{*}{ Model } & \multicolumn{4}{|c|}{ Zero process } & \multicolumn{8}{|c|}{ Count process } \\
\hline & $\begin{array}{l}\text { Milkweed } \\
\text { density* }\end{array}$ & $\begin{array}{l}\text { Floral } \\
\text { richness* }\end{array}$ & $\begin{array}{l}\text { Milkweed } \\
\text { density* }\end{array}$ & $\begin{array}{l}\text { Floral } \\
\text { richness* }\end{array}$ & $\begin{array}{l}\text { Road } \\
\text { density }\end{array}$ & $\begin{array}{l}\text { Surrounding } \\
\text { grassland* }\end{array}$ & $\begin{array}{l}\text { Forest } \\
\text { edge } \\
\text { density }\end{array}$ & $\begin{array}{l}\text { Patch } \\
\text { size }\end{array}$ & $\begin{array}{l}\text { Survey } \\
\text { period in } \\
\text { summer* }\end{array}$ & Year & $\stackrel{\Delta}{A I C}$ & $\mathrm{R}^{2}$ \\
\hline 1 & -37.952 & -1.168 & 0.293 & 0.299 & -0.235 & -0.216 & - & - & $\begin{array}{l}\text { middle> } \\
\text { late> } \\
\text { early }\end{array}$ & - & 0.00 & 0.278 \\
\hline 2 & -39.438 & -1.205 & 0.284 & 0.304 & -0.230 & -0.231 & - & 0.081 & $\begin{array}{l}\text { middle> } \\
\text { late> } \\
\text { early }\end{array}$ & - & 1.43 & 0.273 \\
\hline 3 & -37.549 & -1.171 & 0.292 & 0.295 & -0.228 & -0.234 & 0.044 & - & $\begin{array}{l}\text { middle > } \\
\text { late> } \\
\text { early }\end{array}$ & - & 1.58 & 0.275 \\
\hline 4 & -37.975 & -1.163 & 0.293 & .301 & -0.236 & -0.216 & - & - & $\begin{array}{l}\text { middle > } \\
\text { late }> \\
\text { early }\end{array}$ & $\begin{array}{l}2018 \\
> \\
2019\end{array}$ & 2.09 & 0.275 \\
\hline
\end{tabular}

\section{Egg and larva density}

Variability in monarch immatures per $\mathrm{m}^{2}$ was most consistently explained by milkweed density (all 10 of competing best fit models) and year (Table 3 , Fig. 2A). There were more immature monarchs per $\mathrm{m}^{2}$ with higher milkweed densities, and more immature monarchs per $\mathrm{m}^{2}$ in 2019 than in 2018 . As 
with adult monarchs, immatures per $\mathrm{m}^{2}$ were negatively associated with the amount of grassland in the surrounding landscape (4 of 10 competing models, Fig. 2B), but road density had a small positive effect (5 of 10 competing models, Fig. 2C). There tended to be more immatures per $\mathrm{m}^{2}$ in the middle of the season (Table 3). Forest edge density, floral richness, and the interaction effect between surrounding grassland and patch size were not included in any of the best-fit models. Patch size appeared in only two of the models and had small coefficients (Table 3 ).

Table 3

The ten best-fit models $(\triangle \mathrm{AIC}<2)$ predicting monarch egg and larva densities per $\mathrm{m}^{2}$ as a function of predictor variables. Values are the scaled parameter estimates for continuous variables, and order of levels for categorical variables (survey period, year). Dashes indicate that the covariate was excluded from a model. Significant predictor variables $(p<0.05)$ in the full model are denoted with an asterisk. Predictor variables that did not appear in any of the ten best-fit models (floral richness, forest edge density, and the interaction of patch size $\times$ surrounding grassland) are not listed.

\begin{tabular}{|c|c|c|c|c|c|c|c|c|}
\hline Model & $\begin{array}{l}\text { Road } \\
\text { density }\end{array}$ & $\begin{array}{l}\text { Surrounding } \\
\text { grassland }\end{array}$ & Milkweed density* & Patch size & Survey period in summer & Year* & $\Delta \mathrm{AlC}$ & $\mathrm{R}^{2}$ \\
\hline 1 & - & - & 0.652 & - & - & $2019>2018$ & 0.00 & 0.35 \\
\hline 2 & 0.156 & - & 0.662 & - & - & $2019>2018$ & 0.19 & $0.35 \varepsilon$ \\
\hline 3 & - & - & 0.673 & - & middle $>$ late $>$ early & $2019>2018$ & 0.37 & 0.39 \\
\hline 4 & 0.156 & - & 0.683 & - & middle $>$ late $>$ early & $2019>2018$ & 0.55 & 0.398 \\
\hline 5 & - & -0.144 & 0.655 & - & - & $2019>2018$ & 0.70 & 0.360 \\
\hline 6 & 0.153 & -0.140 & 0.665 & - & - & $2019>2018$ & 0.92 & 0.356 \\
\hline 7 & - & -0.150 & 0.676 & - & middle $>$ late $>$ early & $2019>2018$ & 0.95 & $0.40 c$ \\
\hline 8 & 0.154 & -0.146 & 0.687 & - & middle $>$ late $>$ early & $2019>2018$ & 1.15 & 0.398 \\
\hline 9 & - & - & 0.641 & 0.088 & - & $2019>2018$ & 1.53 & 0.360 \\
\hline 10 & 0.162 & - & 0.649 & 0.098 & - & $2019>2018$ & 1.59 & $0.35 \varepsilon$ \\
\hline
\end{tabular}

All competing best-fit models predicting monarch immatures per stem included milkweed density and floral richness (Table 4). Milkweed density had a strong negative relationship with immatures per stem (Fig. 3A), while floral richness had a positive relationship (Fig. 3B). Year was also included in all top ten models, with higher values for monarchs per milkweed stem in 2019. Landscape characteristics of forest edge density (negative effect), surrounding grassland (negative effect), and road density (positive effect) appeared in four or fewer of the top ten models, and generally had small coefficient sizes. Patch size had a small negative effect on immatures per stem in 4 of 10 competing models. Survey period and the interaction effect between surrounding grassland and patch size were not included in any of the top ten models. 
Table 4

The ten best-fit models $(\triangle \mathrm{AIC}<2)$ predicting the relationship between eggs and larvae per stem at a patch and each of the predictor variables. Values are the scaled parameter estimates for continuous variables, and order of levels for categorical variables (survey period, year). Significant predictor variables $(p<0.05)$ in the full model are denoted with an asterisk. Predictor variables that did not appear in any of the ten best-fit models $($ survey

\begin{tabular}{|c|c|c|c|c|c|c|c|c|c|}
\hline Model & $\begin{array}{l}\text { Road } \\
\text { density }\end{array}$ & $\begin{array}{l}\text { Forest edge } \\
\text { density }\end{array}$ & $\begin{array}{l}\text { Surrounding } \\
\text { grassland }\end{array}$ & $\begin{array}{l}\text { Milkweed } \\
\text { density* }\end{array}$ & $\begin{array}{l}\text { Floral } \\
\text { richness* }\end{array}$ & $\begin{array}{l}\text { Patch } \\
\text { size }\end{array}$ & Year* & $\stackrel{\Delta}{A I C}$ & $\mathrm{R}^{2}$ \\
\hline 1 & - & - & - & -0.333 & 0.304 & - & $\begin{array}{l}2019> \\
2018\end{array}$ & 0.00 & 0.283 \\
\hline 2 & 0.146 & - & - & -0.324 & 0.305 & - & $\begin{array}{l}2019> \\
2018\end{array}$ & 0.16 & 0.267 \\
\hline 3 & - & - & -0.159 & -0.332 & 0.310 & - & $\begin{array}{l}2019> \\
2018\end{array}$ & 0.18 & 0.283 \\
\hline 4 & 0.141 & - & -0.155 & -0.323 & 0.310 & - & $\begin{array}{l}2019> \\
2018\end{array}$ & 0.40 & 0.266 \\
\hline 5 & - & -0.120 & - & -0.330 & 0.315 & - & $\begin{array}{l}2019> \\
2018\end{array}$ & 1.02 & 0.276 \\
\hline 6 & - & - & - & -0.311 & 0.299 & -0.125 & $\begin{array}{l}2019> \\
2018\end{array}$ & 1.03 & 0.285 \\
\hline 7 & 0.140 & - & - & -0.304 & 0.301 & -0.117 & $\begin{array}{l}2019> \\
2018\end{array}$ & 1.30 & 0.267 \\
\hline 8 & - & - & -0.144 & -0.314 & 0.306 & -0.102 & $\begin{array}{l}2019> \\
2018\end{array}$ & 1.56 & 0.284 \\
\hline 9 & 0.127 & -0.087 & - & -0.323 & 0.313 & - & $\begin{array}{l}2019> \\
2018\end{array}$ & 1.72 & 0.263 \\
\hline 10 & - & -0.128 & - & -0.306 & 0.312 & -0.135 & $\begin{array}{l}2019> \\
2018\end{array}$ & 1.87 & 0.277 \\
\hline
\end{tabular}

\section{Discussion}

Planning and managing butterfly habitat conservation and restoration can be improved by understanding how use of a site is affected by landscapeand patch-scale characteristics (Matter and Roland 2002). In grassland patches occurring across two orthogonal landscape gradients of patch size and grassland in the surrounding landscape, higher milkweed density resulted in more monarch adults at patches, and was in turn associated with higher egg and larval density. Furthermore, we found a negative association between the amount of potential monarch habitat in the surrounding landscape and adult monarch density in a patch and, to a lesser extent, egg and larva density. Interestingly, patch size did not affect monarch adult abundance along the transects, nor was there a significant effect of the interaction between patch size and the amount of habitat in the surrounding landscape. These findings suggest that high-quality patches of habitat occurring in landscapes with relatively few other habitats supported the highest densities of immature and adult monarchs, irrespective of patch size.

\section{Landscape-level effects}

Our results document the importance of considering the surrounding landscape when choosing where to create new monarch habitat. The amount of habitat (both grassland and roadsides) in the surrounding landscape had a strong negative relationship with adult monarch abundance at a patch. A similar, albeit weaker pattern in egg and larval density per $\mathrm{m}^{2}$ suggested that higher adult monarch densities at patches with less habitat in the surrounding landscape translate into higher egg and larva densities. These relationships suggest that landscapes in which habitat is limited will be more valuable monarch restoration targets than landscapes where habitat is already abundant. It is not clear from this study what mechanism may be influencing this pattern. While some studies have found a positive correlation between the amount of preferred habitat in the surrounding landscape and insect abundance (Chaplin-Kramer et al. 2011), more recent syntheses suggest that the patterns may be more species and context dependent than previously observed (Kleijn et al. 2018, Karp et al. 2018). Our findings suggest that in a landscape with less overall grassland available adult monarchs could become concentrated in the few grasslands that are available to them, though this hypothesis needs to be more thoroughly tested.

Forest edge density on a landscape scale did not affect monarch abundance. This result could have been due to forest edges playing dual, opposing roles as both a barrier to monarch flight (Ries \& Debinski 2001) and as habitat containing milkweed and blooming plants. It is also possible that we saw no effect from forest edge density because this metric is more influential on a smaller, more localized spatial scale than our $10-\mathrm{km}$ metric. 
The relationship between patch size and butterfly density is like to vary with species' vagility and level of host plant specialization. While the resource concentration hypothesis posits that specialist herbivore insects are more likely to find and linger within larger habitat patches (Root 1973 , Hill et al. 1996), we found that patch size did not predict adult monarch density. Previous researchers reported a positive effect of patch size on monarchs (Davis et al. 2007, Dinsmore et al. 2019). Patch size assessment differed between our study and theirs, which may account for different results. We measured the total area of contiguous grassland as the patch, whereas previous studies measured the amount of grassland within a smaller area $(\sim$ $1 \mathrm{~km}$ ) surrounding the spot at which monarch density was assessed. This lack of response to local patch area is observed in other lepidopterans such as the diamondback moth (Plutella xylostella) and the great spangled-fritillary (Speyeria cybele) (Grez \& González 1995, Davis 2007) due in part to their ability to disperse widely, an ability shared by monarchs.

We found weak evidence that smaller patches had higher densities of monarch immatures. This finding aligns with the results of Grant et al. (2018) who suggested that small patches contribute to monarch recruitment, though this effect of patch size was attributed to an effect of connectivity. We found no support for an interaction between patch size and the amount of surrounding grassland; isolated patches, regardless of their size, contained the highest density of adult monarchs. Strong fliers, like monarchs, may easily pass over habitat boundaries and through inhospitable landscapes to both small and large patches (Ries and Debinski 2001).

\section{Patch-quality effects}

One of the strongest patterns we observed was the effect of local patch quality on the density of both adult and immature monarchs. Milkweed stem density within the patch had a strong positive relationship with immatures per $\mathrm{m}^{2}$ and adult monarch abundance. This finding suggests that an increased rate of gain of adult monarchs (or alternatively, longer stays within the patch) exceeds the resource dilution effect of females ovipositing across more host plants, evidenced by the negative relationship between milkweed density and immatures per stem (Otway et al. 2005, Stephens \& Myers 2012). This pattern (i.e., rate of gain exceeding dilution) would also occur if females visiting high-density milkweed patches experience increased fecundity because their searching time is decreased. While we did not measure oviposition rates by individual females, the fact that we saw more adults in patches with higher milkweed densities suggests that our finding of more immatures per unit area is at least partly due to more females or longer stays in the patch, and not just more eggs per female. The positive relationship we found between milkweed density and immatures per $\mathrm{m}^{2}$ is in line with the resource concentration hypothesis which posits that that denser stands of host plants will recruit more specialist herbivores than sparse stands (Hambäck \& Englund 2005).

While Kasten et al. (2016) found an asymptote of egg density with increasing milkweed density in the roadsides they studied, immature monarch density per unit area continued to increase with increasing milkweed density in our study. The reasons for this difference are not immediately apparent, since egg and larva density leveled off at 0.6 milkweed stems per $\mathrm{m}^{2}$ in the Kasten et al. (2016) study, while in our study immature density was still increasing at 5 milkweed stems per $\mathrm{m}^{2}$. Our findings suggest that more adult monarchs are attracted to grassland patches with higher milkweed densities or that they stay longer once they get to a patch, and that this results in increased monarch recruitment, at least in the $A$. syriaca dominated grasslands we studied (Table 1).

Patches with lower milkweed densities had more eggs and larvae per stem; however, overall more eggs and larvae per $\mathrm{m}^{2}$ were found in patches with higher milkweed densities, indicating a net effect of more milkweeds producing more monarchs (Table 4; Fig. 3A). These results align with others who have surveyed monarch eggs and larvae on a per stem basis (Kasten et al. 2016). The per stem approach to reporting immatures is often used in reporting associations between milkweeds and monarchs (e.g. Pleasants and Oberhauser 2013, Pleasants 2015, Stenoin et al. 2015, etc.) and can help land managers understand how many butterflies will result from planting a certain number of stems. This effect is expected if the same number of eggs were spread out over a larger number of host plants - if eggs were being diluted over more host plants. However, the fact that we found both more adults and more immatures on a per area basis with increasing milkweed density documents the importance of assessing egg and larva density on a per area basis. This metric predicts population-level outcomes that scale with both habitat area and host plant density and thus provide a better understanding of how much habitat is needed to support a sustainable monarch population. The positive relationship between immatures per $\mathrm{m}^{2}$ and milkweed density indicates that planting more milkweed stems should result in higher monarch recruitment at a patch.

Higher floral richness led to more adult monarchs. However, the lack of an effect of floral richness on immature density suggests that milkweed in areas with poor floral richness support monarch recruitment despite offering a smaller reward for adults. Previous research suggests that butterfly dispersal is tied to nectar resources (Peterson 1997), and our finding that adult abundance increases with floral richness supports previous findings. The lack of correlation between immature monarch density and floral richness indicates, however, that females still oviposited at patches with lower nectar diversity, but possibly left more quickly in search of nectar resources.

\section{Conclusion}

Monarchs must be able to find and use habitat patches during their breeding season if the population is to reach sustainable levels. If conservation efforts are not informed by an understanding of the effects of landscape components on monarch patch use, restorations may take place at scales or in landscapes that do not result in the greatest benefits to the population. Similarly, in order to avoid creating suboptimal habitat for monarchs, restoration managers should consider how milkweed density and flowering species richness contribute to monarch recruitment. 
We found more adult monarchs in isolated patches, reflecting the importance of creating, improving, and expanding patches in landscapes where little habitat exists. Our findings on the impacts of patch quality reinforce the importance of plentiful milkweed stems; higher stem densities resulted in higher densities of eggs and larvae per $\mathrm{m}^{2}$. While the existing milkweed densities in our study sites did not identify a point of diminishing returns with respect to milkweed density, previous research (Kasten et al. 2016) suggests that this point may exist.

Land managers must also decide how many additional flowering species to include in restorations focused on monarch conservation based on cost and other considerations. We found more adult monarchs in sites with more flowering species. However, our finding that blooming plant diversity did not affect egg and larva density suggests that females lay just as many eggs in less florally diverse patches and that our observation of more adults might be due to females staying in more diverse patches longer to nectar without laying more eggs.

\section{Declarations}

Funding:

The research leading to these results received funding from the U. S. Geological Survey under Agency Project number G17AC00393.

Conflicts of interest/Competing interests:

The authors have no relevant financial or non-financial interests to disclose.

Ethics approval:

Not applicable.

Consent to participate:

Not applicable.

Consent for publication:

The Authors hereby consents to publication of this work in any and all Landscape Ecology publications.

Availability of data and material:

Data and materials available upon request; DOI will be active upon publication.

Code availability:

Code available upon request; DOI will be active upon publication.

Authors' contributions:

Karen Oberhauser and Claudio Gratton contributed to the study conception and design. Material preparation, data collection and analysis were performed by A. Skye Bruce. The first draft of the manuscript was written by A. Skye Bruce and all authors commented on previous versions of the manuscript. All authors read and approved the final manuscript.

\section{References}

Altizer, A., \& Oberhauser, K. (1999). Effects of the protozoan parasite Ophryocystis elektroscirrha on the fitness of monarch butterflies (Danaus plexippus). Journal of Invertebrate Pathology, 74(1), 76-88. https://doi.org/10.1006/jipa.1999.4853

Bartoń, K. (2019). MuMIn: Multi-Model Inference. R package version 1.43.15.

https://CRAN.R-project.org/package=MuMIn

Bender, D.J., Tischendorf, L., \& Fahrig, L. (2003). Using patch isolation metrics to predict animal movement in binary landscapes. Landscape Ecology, 18(1), 17-39. https://doi.org/10.1023/A:1022937226820

Brooks, M.E., Kristensen, K., van Benthem, K.J., Magnusson, A., Berg, C.W., Nielsen, A., Skaug, H.J., Maechler, M., and Bolker, B.M. (2017). glmmTMB balances speed and flexibility among packages for zero-inflated generalized linear mixed modeling. The R Journal, 9(2), 378-400.

Burnham, K.P., Anderson, D.R. (2002). Model Selection and Multimodel Inference: A Practical Information-Theoretic Approach, 2nd edition. SpringerVerlag New York, Inc., New York, USA. 
Cariveau, A.B., Holt, H.L., Ward, J.P., Lukens, L., Kasten, K., Thieme, J., Caldwell, W., Tuerk, K., Baum, K. A., Drobney, P., Drum, R. G., Grundel, R., Hamilton, K., Hoang, C., Kinkead, K., Mclntyre, J., Thogmartin, W.E., Turner, T., Weiser, E.L., \& Oberhauser, K. (2019). The Integrated Monarch Monitoring Program: From design to implementation. Frontiers in Ecology and Evolution, 7. https://doi.org/10.3389/fevo.2019.00167

Center for Biological Diversity, Center for Food Safety, Xerces Society \& Brower, L.P. (2014). Petition to protect the monarch butterfly (Danaus plexippus plexippus) under the Endangered Species Act. http://www.centerforfoodsafety.org/legal-actions. Accessed 26 July 2020.

Chaplin-Kramer, R., O’Rourke, M.E., Blitzer, E.J., Kremen, C. (2011). A meta-analysis of crop pest and natural enemy response to landscape complexity. Ecology Letters14, 922-932. https://doi.org/10.1111/j.1461-0248.2011.01642.x

Davis, J.D., Debinski, D.M., and Danielson, B.J. (2007). Local and landscape effect on the butterfly community in fragmented Midwest USA prairie habitats. Landscape Ecology, 22, 1341-1354. doi: 10.1007/s10980-007-9111-9

Dewitz, J. (2019). National Land Cover Database (NLCD) 2016 Products: U.S. Geological Survey data release, https://doi.org/10.5066/P96HHBIE.

Dinsmore, S., Vanausdall, R., Murphy, K., Kinkead, K., \& Frese, P. (2019). Patterns of monarch site occupancy and dynamics in lowa. Frontiers in Ecology and Evolution, 7, 169. https://doi.org/10.3389/fevo.2019.00169

Fahrig, L. (2013). Rethinking patch size and isolation effects: The habitat amount hypothesis. Journal of Biogeography, 40(9), $1649-1663$. https://doi.org/10.1111/jbi.12130

Esri Inc. (2018). ArcGIS Desktop (Version 10.6). Esri Inc.

Grant, T.J., Parry, H.R., Zalucki, M.P., \& Bradbury, S.P. (2018). Predicting monarch butterfly (Danaus plexippus) movement and egg-laying with a spatially-explicit agent-based model: The role of monarch perceptual range and spatial memory. Ecological Modelling, 374, 37-50.

https://doi.org/10.1016/j.ecolmodel.2018.02.011

Hambäck, P.A., \& Englund, G. (2005). Patch area, population density and the scaling of migration rates: The resource concentration hypothesis revisited: Density-area relations in sources and sinks. Ecology Letters, 8(10), 1057-1065. https://doi.org/10.1111/j.1461-0248.2005.00811.x

Hartig, F. (2020). DHARMa: residual diagnostics for hierarchical (multi-level / mixed) regression models. R package, version 0.3.2.0. http://florianhartig.github.io/DHARMa/

Hesselbarth, M.H.K., Sciaini, M., With, K.A., Wiegand, K., \& Nowosad, J. (2019). Landscapemetrics: an open-source $r$ tool to calculate landscape metrics. Version 1.2.2 Ecography, 42, 1648-1657.

Hill, J.K., Thomas, C.D., \& Lewis, O.T. (1996). Effects of habitat patch size and isolation on dispersal by Hesperia comma butterflies: implications for metapopulation structure. Journal of Animal Ecology, 65(6), 725-735. JSTOR. https://doi.org/10.2307/5671

Karp, D., Chaplin-Kramer, R., Meehan, T., Poppenborg Martin, E., Declerck, F., Grab, H.,

Gratton, C., Hunt, L., Larsen, A., Martínez-Salinas, A., O’Rourke, M., Rusch, A., Poveda, K., Jonsson, M., Rosenheim, J., Schellhorn, N., Tscharntke, T., Wratten, S., Zhang, W., Zou, Y. (2018). Crop pests and predators exhibit inconsistent responses to surrounding landscape composition. Proceedings of the National Academy of Sciences, 115, 201800042. https://doi.org/10.1073/pnas.1800042115

Kasten, K., Stenoien, C., Caldwell, W., \& Oberhauser, K.S. (2016). Can roadside habitat lead monarchs on a route to recovery? Journal of Insect Conservation, 20(6), 1047-1057. https://doi.org/10.1007/s10841-016-9938-y

Kleijn, D., Linders, T.E.W., Stip, A., Biesmeijer, J.C., Wäckers, F.L., Bukovinszky, T. (2018).

Scaling up effects of measures mitigating pollinator loss from local- to landscape-level population responses. Methods in Ecology and Evolution, 9 , 1727-1738. https://doi.org/10.1111/2041-210X.13017

Lüdecke, D., Makowski, D., Waggoner, P., \& Patil, I. (2020). Assessment of Regression Models Performance. CRAN. 10.5281/zenodo.3952174

Lukens, L., Kasten, K., Stenoien, C., Cariveau, A., Caldwell, W., \& Oberhauser, K. (2020). Monarch Habitat in Conservation Grasslands. Frontiers in Ecology and Evolution, 8. https://doi.org/10.3389/fevo.2020.00013

Matter, S.F., Roland, J. (2002). An experimental examination of the effects of habitat quality on the dispersal and local abundance of the butterfly Parnassius smintheus. Ecological Entomology, 27, 308-316. https://doi.org/10.1046/j.1365-2311.2002.00407.x

Matter, S.F., Roslin, T., Roland, J., Kaitala, V. (2005). Predicting immigration of two species in contrasting landscapes: effects of scale, patch size and isolation. Oikos, 111, 359-367. 
Oberhauser, K. (2012). Tachinid flies and monarch butterflies: citizen scientists document parasitism patterns over broad spatial and temporal scales. American Entomologist, 58(1), 19-22. https://doi.org/10.1093/ae/58.1.0019

Oberhauser, K.S., Prysby, M.D., Mattila, H.R., Stanley-Horn, D.E., Sears, M.K., Dively, G., Olson, E., Pleasants, J.M., Lam, W.-K.F., Hellmich, R.L. (2001). Temporal and spatial overlap between monarch larvae and corn pollen. Proceedings of the National Academy of Sciences of the United States of America, 98, 11913. https://doi.org/10.1073/pnas.211234298

Oberhauser, K., Wiederholt, R., Diffendorfer, J.E., Semmens, D., Ries, L., Thogmartin, W.E., Lopez-Hoffman, L., Semmens, B. (2017). A trans-national monarch butterfly population model and implications for regional conservation priorities. Ecological Entomology, 42, 51-60. https://doi.org/10.1111/een.12351

Otway, S. J., Hector, A., Lawton, J. H. (2005). Resource dilution effects on specialist insect herbivores in a grassland biodiversity experiment. Journal of Animal Ecology, 74, 234-240.

Paradis E. \& Schliep K. (2018). ape 5.0: an environment for modern phylogenetics and evolutionary analyses in R. Bioinformatics, 35, 526-528.

Peterson, M. (1997). Host plant phenology and butterfly dispersal. Ecology, 78, 167-180.

Pleasants, J. (2017). Milkweed restoration in the Midwest for monarch butterfly recovery: Estimates of milkweeds lost, milkweeds remaining and milkweeds that must be added to increase the monarch population. Insect Conservation and Diversity, 10(1), 42-53. https://doi.org/10.1111/icad.12198

Pleasants, J.M., \& Oberhauser, K.S. (2013). Milkweed loss in agricultural fields because of herbicide use: Effect on the monarch butterfly population. Insect Conservation and Diversity, 6(2), 135-144. https://doi.org/10.1111/j.1752-4598.2012.00196.x

Pleasants, J.M. (2015). Monarch butterflies and agriculture. Monarchs in a changing world: biology and conservation of an iconic butterfly. Ithaca, NY. Cornell University Press. 169-178.

Pollard, E. (1977). A method for assessing changes in the abundance of butterflies. Biological Conservation, 12(2), 115-134. https://doi.org/10.1016/0006-3207(77)90065-9

Potts, S.G., Woodcock, B.A., Roberts, S.P.M., Tscheulin, T., Pilgrim, E.S., Brown, V.K.,

Tallowin, J.R. (2009). Enhancing pollinator biodiversity in intensive grasslands. Journal of Applied Ecology, 46, 369-379. https://doi.org/10.1111/j.1365-2664.2009.01609.x

R Core Team. (2019). R: A language and environment for statistical computing. R Foundation for Statistical Computing, Vienna, Austria. https://www.R-project.org/

Ries, L., and Debinski, D.M. (2001). Butterfly responses to habitat edges in the highly fragmented prairies of Central lowa. Journal of Animal Ecology, $70,840-852$.

https://doi.org/10.1046/j.0021-8790.2001.00546.x

Root, R.B. (1973). Organization of a plant-arthropod association in simple and diverse habitats: the fauna of collards (Brassica oleracea). Ecological Monographs, 43(1), 95-124. JSTOR. https://doi.org/10.2307/1942161

Saunders, S.P., Ries, L., Oberhauser, K.S., Thogmartin, W.E., Zipkin, E.F. (2018). Local and cross-seasonal associations of climate and land use with abundance of monarch butterflies Danaus plexippus. Ecography, 41, 278-290. https://doi.org/10.1111/ecog.02719

Semmens, B.X., Semmens, D.J., Thogmartin, W.E., Wiederholt, R., López-Hoffman, L., Diffendorfer, J.E., Pleasants, J.M., Oberhauser, K.S., \& Taylor, O.R. (2016). Quasi-extinction risk and population targets for the Eastern, migratory population of monarch butterflies (Danaus plexippus). Scientific Reports, 6, 23265. https://doi.org/10.1038/srep23265

Shono, H. (2008). Application of the Tweedie distribution to zero-catch data in CPUE analysis. Fisheries Research, 93(1), $154-162$. https://doi.org/10.1016/j.fishres.2008.03.006

Stenoien, C., Nail, K.R., Zalucki, J.M., Parry, H., Oberhauser, K.S., \& Zalucki, M.P. (2018). Monarchs in decline: A collateral landscape-level effect of modern agriculture. Insect Science, 25(4), 528-541. https://doi.org/10.1111/1744-7917.12404 
Stephens, A.E.A., Myers, J.H., 2012. Resource concentration by insects and implications for plant populations. Journal of Ecology, $100,923-931$. https://doi.org/10.1111/j.1365-2745.2012.01971.x

Thogmartin, W.E., Diffendorfer, J.E., López-Hoffman, L., Oberhauser, K., Pleasants, J., Semmens, B.X., Semmens, D., Taylor, O.R., \& Wiederholt, R. (2017). Density estimates of monarch butterflies overwintering in central Mexico. PeerJ, 5, e3221. https://doi.org/10.7717/peerj.3221

Thogmartin, W.E., López-Hoffman, L., Rohweder, J., Diffendorfer, J., Drum, R., Semmens, D., Black, S., Caldwell, I., Cotter, D., Drobney, P., Jackson, L.L., Gale, M., Helmers, D., Hilburger, S., Howard, E., Oberhauser, K., Pleasants, J., Semmens, B., Taylor, O., Ward, P., Weltzin, J.F., and Wiederholt, R. (2017). Restoring monarch butterfly habitat in the Midwestern US: 'all hands on deck.' Environmental Research Letters, 12(7), 074005.

https://doi.org/10.1088/1748-9326/aa7637

Thogmartin, W.E., Wiederholt, R., Oberhauser, K., Drum, R.G., Diffendorfer, J.E., Altizer, S., Taylor, O.R., Pleasants J., Semmens, D., Semmens, B., Erickson, R., Libby, K., \& Lopez-Hoffman, L. (2017). Monarch butterfly population decline in North America: Identifying the threatening processes. Royal Society Open Science, 4(9), 170760. https://doi.org/10.1098/rsos.170760

United States Census Bureau. (2019). TIGER/Line Shapefiles Technical Documentation. 1-138. https://www2.census.gov/geo/pdfs/mapsdata/data/tiger/tgrshp2019/TGRSHP2019_TechDoc.pdf

1. S. Fish and Wildlife Service. (2020). Endangered and Threatened Species: 12-Month Finding for the Monarch Butterfly. Federal Register 2020 Dec $17 ; 85: 81813-81822$.

https://www.federalregister.gov/documents/2020/12/17/2020-27523/endangered-and-threatened-wildlife-and-plants-12-month-finding-for-themonarch-butterfly. Accessed 26 January 2021.

Walker, K. (2020). tigris: Load Census TIGER/Line Shapefiles. R package version 0.9.4.

https://CRAN.R-project.org/package=tigris

Zalucki, M.P., Parry, H.R., \& Zalucki, J.M. (2016). Movement and egg laying in Monarchs: To move or not to move, that is the equation. Austral Ecology, 41(2), 154-167. https://doi.org/10.1111/aec.12285

Zalucki, M.P., Kitching, R.L. (1982). The analysis and description of movement in adult

Danaus plexippus L. (Lepidoptera: Danainae). Behaviour,80, 174-197.

Zalucki, M.P. (1983). Simulation of movement and egg laying in Danaus plexippus

(Lepidoptera: Nymphalidae). Researches on Population Ecology, 25, 353-365.

\section{Figures}



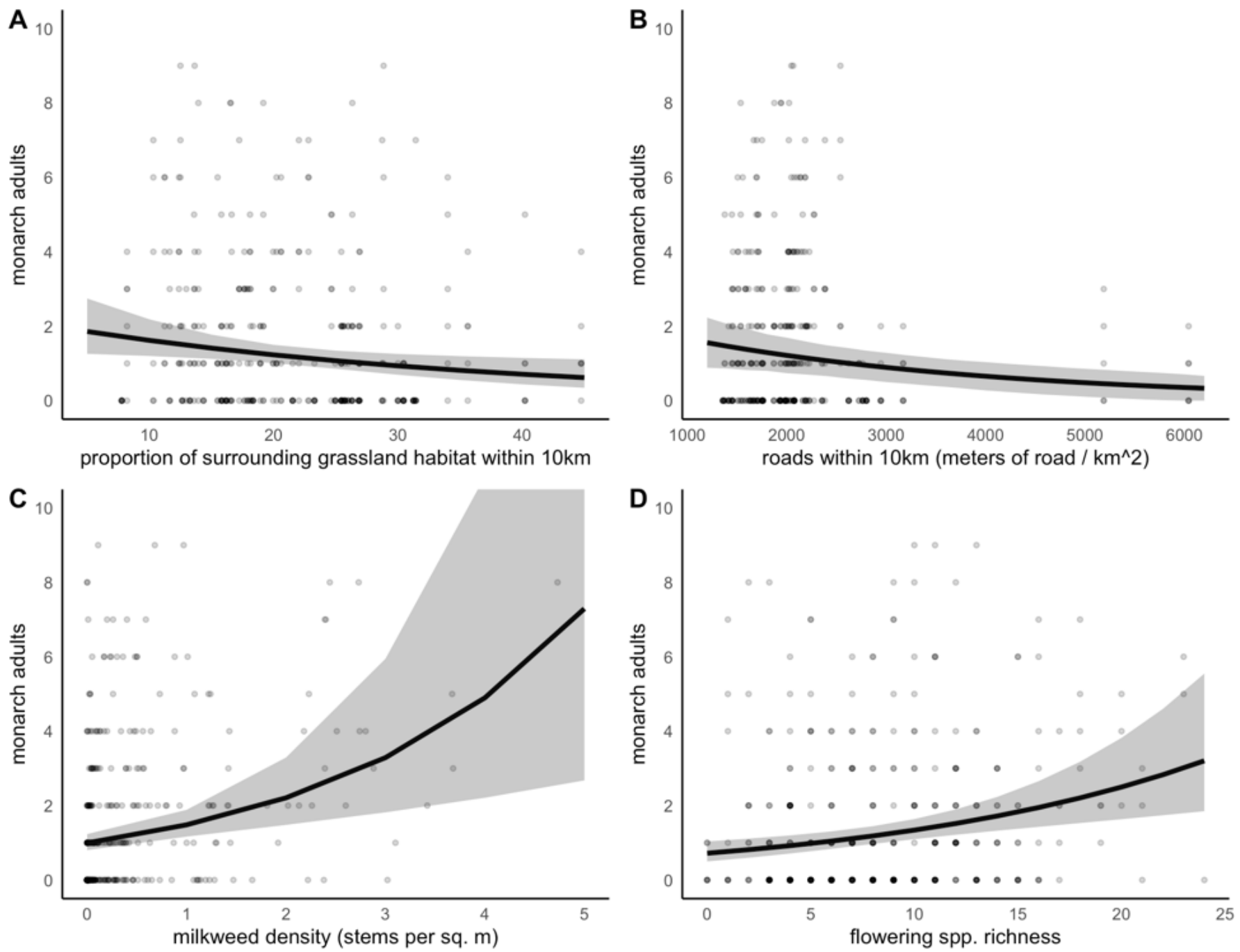

Figure 1

Plots of relationships between monarch adult abundance along the transect and the predictor variables that were in the top selected model based on AIC (Model 1, Table 2). These predictor variables were also the most commonly included in the top ten models of monarch adult abundance. The gray ribbon represents the $95 \%$ confidence interval. Adult monarch abundance along the transect is $(A)$, negatively associated with the proportion of grassland in the surrounding landscape; (B) negatively associated with road density; (C) positively associated with milkweed density; and (D) positively associated with blooming plant diversity. 

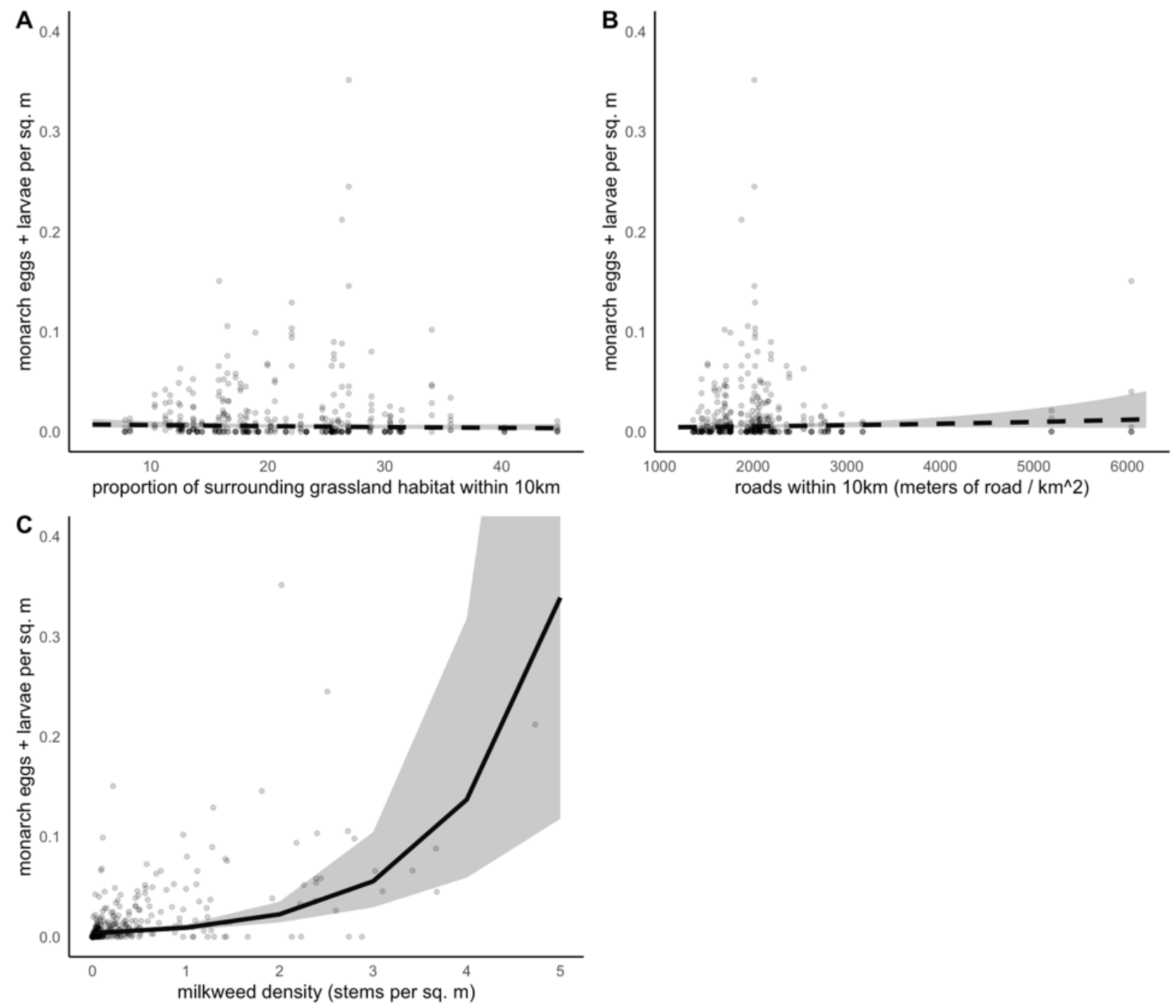

Figure 2

Plots of relationships between monarch eggs and larvae per $\mathrm{m} 2$ at a patch and the predictor variables that were among the best-fit models based on AIC (see Table 3). Solid lines indicate significant predictor variables. Dashed lines indicate nonsignificant predictor variables but were included in $\geq 4 / 10$ of the best-fit models. The gray ribbon represents the $95 \%$ confidence interval. (A) shows the relationship between monarch egg and larva density per $\mathrm{m} 2$ and milkweed density, which was included in all of the top ten models selected based on lowest AIC. (B) shows the relationship between egg and larva density and the amount of grassland in the surrounding area within $10 \mathrm{~km}$ of the patch. (C) shows the relationship between egg and larva density per $\mathrm{m} 2$ and road density in the landscape. Model 6 (Table 3 ) was used to plot these relationships because it was the model with the lowest AIC that contained the three variables most commonly found in the top ten models. 

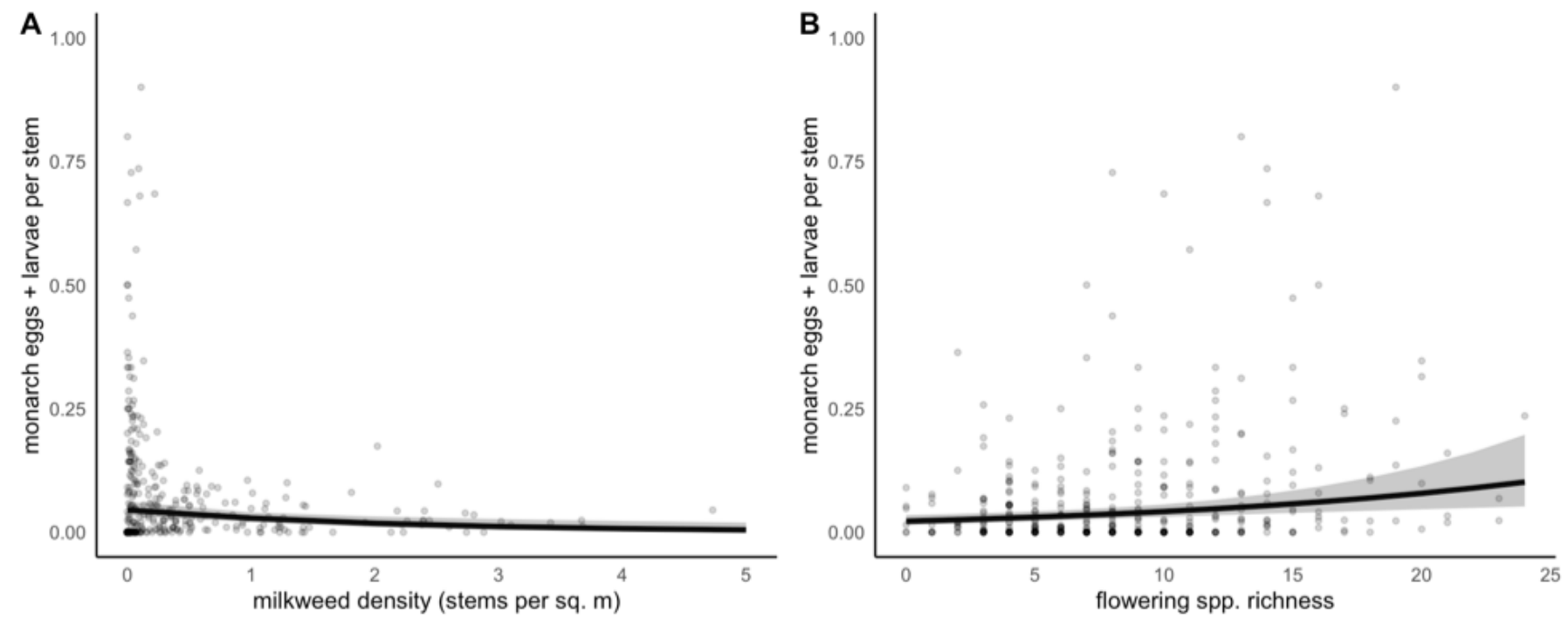

\section{Figure 3}

Relationships between monarch egg and larva per stem density at a patch and the predictor variables that were in the top selected model based on AIC. The gray ribbon represents the $95 \%$ confidence interval. Monarch egg and larva per stem density is (A), negatively associated with milkweed density; and (B) positively associated with floral richness in the patch.

\section{Supplementary Files}

This is a list of supplementary files associated with this preprint. Click to download.

- AppendixA.png

- AppendixB.png 